\section{Interações entre práticas alimentares e identidades: ressignificando a escola pública e a alimentação escolar}

\author{
Interactions between dietary habits and \\ identities: redefining public schools \\ and school meals
}

Edleuza Oliveira Silva 1,2

Lígia Amparo-Santos 2

Micheli Dantas Soares 1

\section{Resumo}

Estudos sobre práticas alimentares no contexto do Programa Nacional de Alimentação Escolar (PNAE) têm apontado um paradoxo: de um lado, o PNAE avançou como política fundamentada no direito humano à alimentação adequada e, de outro, ainda apresenta um viés assistencialista que tende a contribuir para identidades estigmatizadas. Considerando esse contexto, um estudo foi realizado, objetivando compreender as interações entre práticas alimentares em torno da alimentação escolar e identidades. A abordagem etnográfica se configurou como percurso teórico-metodológico, tomando, como cenário, uma escola pública no Município de Santo Antônio de Jesus, Bahia, Brasil, do segundo ciclo do Ensino Fundamental. A etnografia foi realizada durante sete meses, sendo constituída de observação do cotidiano alimentar da escola, com registros em diário de campo, assim como realização de 23 entrevistas com alunos e atores-chave. A análise do material produzido consistiu em um exercício hermenêutico e categorização dos temas que emergiram. Este artigo é um recorte dessa investigação em que duas categorias são apresentadas: a primeira, "A escola é nossa", analisa um movimento de ressignificação da escola ante uma identidade estigmatizada; a segunda, "A comida é o que une", apresenta a alimentação escolar como um elemento estruturante das identidades dos alunos e da própria escola. Os achados apontam também o quanto o diálogo entre o campo da educação e o campo da alimentação e nutrição pode contribuir para que a alimentação escolar integre as práticas escolares não como um mero suporte nutricional, mas como comida que valoriza a escola pública e seus sujeitos.

Alimentação Escolar; Hábitos Alimentares; Identificação Social; Escolas; Alunos

\author{
Correspondência \\ E. O. Silva \\ Universidade Federal do Recôncavo da Bahia. \\ Av. Carlos Amaral 1015, Santo Antônio de Jesus, BA \\ 44574-490, Brasil. \\ edleuza@ufrb.edu.br \\ 1 Universidade Federal do Recôncavo da Bahia, Santo Antônio \\ de Jesus, Brasil. \\ 2 Universidade Federal da Bahia, Salvador, Brasil.
}




\section{Introdução}

As práticas alimentares na escola têm sido tema relevante da agenda internacional, face às situações de insegurança alimentar e nutricional que acometem estudantes, dentre as quais, incluem-se a fome e o incremento da obesidade, além de outros problemas de saúde associados à alimentação na modernidade. Dada a diversidade de modalidades que ocorre nos diversos sistemas educacionais, há uma vasta publicação que discute a temática sob várias abordagens. Nesse bojo, estudos vêm discutindo a relação entre práticas alimentares na escola e constituição de identidades de estudantes 1,2,3,4,5,6,7,8,9,10,11,12,13, de tal modo que é possível assumir que crianças e adolescentes vivenciam, na escola, processos identitários como formas de se relacionar com o mundo, de se identificar com os pares, de agir por si mesmos, de construir relações de pertença, e as práticas alimentares que realizam na escola estão diretamente implicadas nesses processos.

No Brasil, uma revisão dos estudos sobre o tema apontou que a maioria se concentra no contexto do Programa Nacional de Alimentação Escolar (PNAE), dado o alcance dessa política ${ }^{14}$. Esta revisão trouxe à tona o paradoxo a partir do qual, a despeito do arcabouço jurídico normativo do PNAE ter sido revisitado nas últimas décadas 15 , corroborando, em última instância, para que a alimentação escolar fosse reconhecida como uma política pública fundamentada no Direito Humano à Alimentação Adequada (DHAA) e na Segurança Alimentar e Nutricional, ainda persiste um viés assistencialista no âmbito do cotidiano das escolas, que reduz a alimentação escolar a uma comida para alunos pobres, atribuindo-lhes uma identidade estigmatizada ${ }^{14}$. Com base no resultado dos estudos citados acima sobre a relação entre práticas alimentares em torno da alimentação escolar e processos identitários de alunos, propusemos uma investigação empírica para compreender que elementos subjazem a essa realidade.

Assumimos como uma possibilidade de compreensão das práticas alimentares na escola a teoria da prática de Bourdieu 16, visto que se faz necessário compreender as condições sócio-históricas em que são instituídas e, ao mesmo tempo, dialogando com os pressupostos socioantropológicos da alimentação 17,18,19. O estudo das práticas alimentares requer múltiplos olhares que permitam compreender as experiências dos sujeitos com a alimentação, implicando em observar o que comem, por que, como, quando e com quem comem e, principalmente, as interações produzidas no interior dessas práticas. Para tanto, o interacionismo simbólico se configura como uma abordagem teórica que possibilita compreender os significados como um produto social, tendo, em vista, que o significado das coisas para um sujeito é resultante das interações que estabelece com outros sujeitos, em meio às relações de forças nas diversas situações do cotidiano 20,21 .

Por sua vez, a discussão sobre processos identitários na escola requer uma reflexão mais ampla sobre a temática da identidade como uma construção social de significados a partir de interações em um dado contexto sócio-histórico e suas relações de poder 22,23,24. Castells 22 amplia essa discussão, propondo três perspectivas de entendimento dos processos identitários: (i) identidades legitimadoras e hegemônicas, produzidas pelas instituições dominantes, definindo quem é incluído ou excluído; (ii) identidades de resistência, produzidas por sujeitos que estão em situação de exclusão e de estigmatização; e (iii) identidades de projeto, produzidas por sujeitos que buscam redefinir suas posições na sociedade. Tais proposições são pertinentes para compreender o objeto e o contexto de investigação deste estudo, haja vista que a escola se trata de uma instituição social em que há relações de poder, de produção de identidades hegemônicas e, por conseguinte, produz processos de resistências e ressignificações pelos sujeitos.

$\mathrm{Na}$ esteira dessa discussão, podemos retornar à visão bourdieana feita sobre a escola como aparelho de reprodução social que pode perpetuar e legitimar as desigualdades sociais 25,26. Partindo desse ponto, é preciso destacar que, no interior da escola, operam diferentes matrizes teóricas sobre a educação, dentre as quais, encontram-se teorias mais conservadoras e outras problematizadoras e emancipatórias, estas mais alinhadas às possibilidades de enfrentamento dos sistemas de dominação 27,28.

Ante esse panorama, buscou-se compreender as interações entre as práticas alimentares em torno da alimentação escolar e os processos identitários dos estudantes, considerando o contexto sócio-histórico do PNAE e da instituição escolar. Tal objetivo direcionou a realização de uma investigação mais ampla 29. Este artigo é um recorte dessa investigação que versa sobre a ressignificação da escola e da alimentação escolar como resultante dos processos identitários dos alunos. 


\section{A metodologia do estudo}

Tendo em vista a natureza do objeto proposto, a abordagem etnográfica se configurou apropriada para apreender o fenômeno a partir do seu lócus, buscando compreender como as pessoas percebem sua própria realidade no cotidiano, identificando e interpretando as formas simbólicas que a constituem: palavras, imagens, comportamentos, sentimentos, instituições, isto é, buscou-se identificar seus sistemas de símbolos "em seus próprios termos" através dos quais as pessoas se representam para si mesmas e para os outros 30 .

A população de estudo foi constituída pelos sujeitos de uma escola pública estadual do Município de Santo Antônio de Jesus, Bahia. Esse município integra a região do Recôncavo Baiano, a qual abarca municípios que representam núcleos históricos e culturais do povo brasileiro. Junto com a capital, Salvador, possui a maior população negra do país e um vasto patrimônio da cultura afro-brasileira 31,32 .

A escola estudada situa-se em uma região periférica da cidade, nos limites com a zona rural, mas em um bairro que está em franca expansão influenciada pela implantação da Universidade Federal do Recôncavo da Bahia (UFRB), em 2006, e do Instituto Federal de Educação, Ciência e Tecnologia da Bahia, em 2015. A escola foi criada em 1975 e funcionou na modalidade de Educação Integral de 2014 a 2017, ofertando aula para o segundo ciclo do Ensino Fundamental, ou seja, do sexto ao nono ano, em que os alunos integravam a faixa etária entre 11 a 14 anos. Iniciou o ano letivo de 2017 com uma equipe de trabalho formada por dez professoras, 18 funcionários e 148 alunos, a maioria residente em um conjunto habitacional do programa Minha Casa, Minha Vida.

O trabalho de campo teve duração de sete meses, de fevereiro a agosto de 2017, consistindo em observação, de segunda a sexta, do cotidiano das práticas alimentares na escola, com foco em três momentos: o primeiro, referente ao intervalo de trinta minutos da manhã, que começava com a merenda das 10:00; o segundo, de uma hora, que iniciava com o almoço às 12:00 e, depois, a hora livre; e, por fim, a merenda da tarde, ao término das aulas, por volta das 15:00. Para fins desse estudo, usaremos o termo "merenda", em vez de lanche ou colação, para nos referirmos às pequenas refeições das 10:00 e 15:00, por entender que melhor traduz e representa emicamente essa refeição, distinguindo-se do termo "alimentação escolar", o qual será empregado para se referir ao conjunto de refeições promovidas pelo PNAE.

Além da observação, entrevistas foram realizadas com alunos, professores e funcionários, buscando recolher informações a partir de narrativas sobre a experiência da oferta da comida e do comer na escola. Foram entrevistados 17 alunos, além de seis integrantes da equipe de trabalho: a diretora, a professora articuladora, uma professora, duas cozinheiras e uma auxiliar de serviços gerais. Compreende-se que a produção de narrativas se constitui em um processo de construção identitária também, visto que o sujeito assume uma postura mais reflexiva, reunindo e relacionando suas identidades tanto atribuídas como reivindicadas 33 .

Para a seleção dos alunos para as entrevistas, elegemos critérios que possibilitassem maior diversidade das experiências com o comer na escola, apresentando um ou mais das seguintes características: residir na área rural; consumir a maioria das preparações; repetir refeições; não merendar e/ou não almoçar na escola; trazer outras merendas para a escola; reclamar das refeições servidas. Foram também incluídos alunos convidados aleatoriamente e a partir da indicação de outros alunos. Todas as entrevistas, com duração de até quarenta minutos, foram analisadas, considerando que cada narrativa, mesmo que sucinta, comunicava identidades, e que os silêncios e outros signos de linguagem guardam significados que necessitavam ser compreendidos.

O material produzido foi um diário de campo e 23 entrevistas. Estas foram transcritas e passaram por repetidas escutas. A análise do material produzido consistiu em um exercício hermenêutico que envolveu todo o processo, inclusive a própria fase de produção do material empírico 34 , buscando o máximo de rigor no processo interpretativo e partiu do reconhecimento que os textos antropológicos são interpretações de segunda e terceira mão ${ }^{30}$. A etapa da análise consistiu na ordenação e leitura atenta, reiterativa e interrogativa do material colhido, constituindo um processo de impregnação e saturação das narrativas, em busca de respostas ao objetivo do estudo. Fez-se a identificação de categorias analíticas que emergiram das narrativas dos sujeitos entrevistados e do cotidiano descrito no diário de campo. Buscou-se uma compreensão dos significados comunicados pelos sujeitos participantes de suas experiências com o comer na escola, mediatizada pelos pressupostos teóricos assumi- 
dos para este estudo. Buscou-se também uma fusão da visão do pesquisador com o ponto de vista dos sujeitos participantes, assim como o desafio de analisar o fenômeno em seu contexto presente e, ao mesmo tempo, resgatar e dialogar com o seu horizonte histórico 35.

Este artigo discute os processos de ressignificação das identidades da escola e da própria alimentação escolar como resultante dos próprios processos identitários dos alunos e da gestão da alimentação escolar no âmbito da escola estudada, ou seja, a escola como uma identidade construída coletivamente pelos sujeitos da escola, tendo a alimentação escolar como um elemento estruturante dessa identidade.

Para o escopo deste artigo, destacamos duas categorias de análise. A primeira ("A escola é nossa") analisa um movimento que envolve alunos e os outros sujeitos da escola em um conjunto de práticas e discursos diante de uma identidade estigmatizada atribuída à escola pela comunidade. A segunda ("A comida é o que une") apresenta a alimentação escolar como um elemento estruturante desse processo de reconstrução identitária, por propiciar interações que permitem instituir novos significados tanto à alimentação escolar como aos sentidos de pertencimento dos alunos à escola.

O projeto foi aprovado pelo Comitê de Ética em Pesquisa da UFRB sob o número 2.112.480, em cumprimento às normas da Resolução no 466/2012 do Conselho Nacional de Saúde. Destaca-se que os dados sobre a identificação da escola e dos participantes da pesquisa foram resguardados, sendo atribuídos nomes fictícios.

\section{"A escola é nossa": uma identidade ressignificada coletivamente}

A estrutura física da escola estudada - formato circular, muros altos e circulação dos alunos restrita às áreas passíveis de serem vigiadas - contribuía para uma percepção da escola como uma prisão, por parte de alguns alunos. Por seu turno, funcionários referiam que a maioria dos alunos morava nas "casinhas" - referência ao conjunto habitacional do programa Minha Casa, Minha Vida -, adjetivando-o como um local de tráfico e homicídios. Tal denominação nos faz supor associação da origem social dos alunos às representações estigmatizadas, refletindo nas relações construídas na escola. Essas questões expressam o quanto que a escola apresenta uma dimensão estruturada a reproduzir identidades hegemônicas, por meio de suas práticas e modo de organização. Todavia, não se quer dizer que esse processo se desenvolva de forma homogênea, haja vista os esforços para diálogos e práticas transformadoras.

Rios 36, ao comentar sobre as mudanças e crises da escola na contemporaneidade, postula que sua identidade é dinâmica e está em permanente elaboração, sendo construída no interior do seu contexto social em interação com outras instituições sociais como a família, a comunidade, a igreja, as associações e as empresas. Os sujeitos que constituem a escola refletem crenças e valores dos contextos sociais que os constituem, mas, por outro lado, no cotidiano das práticas escolares, são construídos novos significados que vão refazendo as identidades da escola e dos seus integrantes.

Para compreender essa situação, reportemo-nos, inicialmente, à natureza das práticas. A construção da identidade da escola resulta dos significados produzidos nas interações entre alunos e entre esses e os demais atores da escola, dentre outras. Interações que se dão em meio a práticas, que, por sua vez, estão alicerçadas em habitus. As práticas podem ser interpretadas a partir das condições sociais em que o habitus, que lhe é inerente, foi construído, mas, também, dando conta de entender a situação e as condições sociais em que esse habitus é posto em ação no presente. Habitus, não restrito a condicionamentos, mas como uma matriz para infinitas ações 16 . Ou seja, cada situação alberga a possibilidade de transformação pela inventividade dos sujeitos e pelas interações que estabelecem, pois, se não se deve subestimar o poder das instituições, muito menos, a "liberdade das práticas gazeteiras", prenhes de microliberdades e microrrealidades que deslocam as forças instituídas 37.

Assim, cabe-nos reportar as inventividades dos sujeitos nesse processo de construção identitária na e da escola, buscando ver a situação a partir do ponto de vista do estudante. Entende-se que eles são instados a pertencer à escola, ao serem inseridos nela como alunos. Nesse processo, importa fazer a relação identidade e escola, destacando a categoria aluno, entendida como uma construção social 38,39, com representações arraigadas ao longo da história da educação. Sacristán 39 chama a atenção que a criança e o adolescente são transformados em alunos, esses considerados como não 
adultos a serem conduzidos. Essa discussão sinaliza para a necessidade de refletir como os sujeitos na condição de alunos se percebem e agem nesse contexto educacional.

Todavia, se a escola os constitui como alunos, esses se mobilizam em atos e em discursos para ressignificar identidades não desejadas. Reportando-nos a De Certeau 37, entendendo que certos significados podem ser representações sociais também, uma representação identificada em um dado contexto não indica o que ela significa para os seus usuários, nesse caso, o que diz a comunidade externa ou os professores sobre a escola não significa que é o mesmo que pensam os alunos ou o que eles gostariam de pensar. De Certeau instiga-nos a analisar a representação a partir da percepção de quem não a produziu.

Considerando o exposto, o estudo apontou que os alunos se posicionam frente a uma identidade estigmatizada de escola pública, construindo e apontando para ela novos significados e atributos, tal como expressa a narrativa: "Sempre fui tratada bem, (...) sempre quando eu pedia alguma coisa na diretoria, sempre resolvia meus problemas (...). Eu antigamente não gostava daqui não, porque todo mundo falava, o povo falava que esse colégio é ruim, (...) eu não gostava, pela cabeça do povo eu não gostava" (Íris, 16 anos, oitavo ano).

Todavia, cabe ressaltar que também foram registrados, durante o período de estudo, comentários depreciativos sobre a escola, tais como "essa escola é de pobre", "detesto essa escola", "essa escola só tem ladrão". Entretanto, esses relatos foram mais raros e, quando ocorriam, outros alunos contestavam, mas, que evidenciavam a identificação de uma parcela dos alunos com a imagem estigmatizada da escola e seus sujeitos.

Conquanto, as práticas observadas do cotidiano da escola e as narrativas dos entrevistados comunicam que, também, interessa aos alunos que a escola seja um lugar de pertencimento e reconhecimento e, nessa direção, agem. Como ilustra o registro de que dois alunos do oitavo ano organizaram e enviaram uma carta endereçada ao governador, demonstrando, com texto e fotos, as condições da escola, com destaque para a necessidade de implantação de uma quadra poliesportiva e de refeitório, entre outras reivindicações.

Esse interesse na escola também pode ser resultante de variados graus de percepção do aluno sobre seus recursos em termos de socialização do conhecimento e desenvolvimento de habilidades necessárias à formação do sujeito e sua inserção social. Nesse aspecto, além das atividades escolares cotidianas, sublinha-se o protagonismo dos alunos nos eventos produzidos pela escola. Como exemplo, o projeto Festival Anual de Canção Estudantil (FACE), Artes Visuais Estudantis (AVE) e Tempo de Arte Literária (TAL), nos quais os alunos apresentam criações no campo da pintura, da música e da poesia. Ainda que as atividades estivessem atreladas à pontuação via participação, os resultados pareceram surpreender os próprios alunos, como mostrou a fala: "Eu só fiz mesmo pra ganhar meu ponto, minha nota, aí, na hora que eu fiz, o professor chegou pra mim e falou que a minha poesia tinha sido escolhida pra ficar no livro da escola, no livro de poesias da escola e pra apresentar no FACE-AVE-TAL" (Narciso, 13 anos, oitavo ano).

Nessa esteira, não somente a socialização interessa aos alunos, mas também as vivências de sociabilidade que a escola propicia, como ilustra outra fala de Narciso sobre sua participação como mestre de cerimônia em dois eventos da escola: "Foi, foi tipo assim, eu já tava acostumado porque há um tempo atrás a escola tinha me chamado pra ser mestre de cerimônia do aniversário da escola. Foi eu e minha colega. Aí a gente fez tudo, aí eu fiquei, eu já tava nervoso um pouquinho, só que depois foi normal, tranquilo, me dei bem, todo mundo ficou me elogiando e tal" (Narciso, 13 anos, oitavo ano).

Esse movimento de ressignificação da identidade escolar envolvia também professores e funcionários. Como demonstrou o empenho e o incentivo dos professores para a participação dos alunos nos eventos comemorativos e projetos da escola. Por sua vez, os alunos pareciam surpreender a equipe docente, tal qual foi o comentário de uma professora após uma festa de aniversário da escola, que elogiou as apresentações dos alunos, dizendo "os alunos surpreenderam", denotando que eles comunicaram que podem ser mais do que se espera deles.

Era um movimento também favorecido por uma gestão escolar comprometida com a escola, envidando esforços para envolver a participação de alunos, professores e funcionários, como refere a diretora: "É pensar realmente que nós estamos em um ambiente educacional e que nós devemos tratar esse ambiente como se fosse nosso, como se fosse nossa casa, porque ele é nosso, mas como se estivéssemos na nossa casa, o ambiente é nosso, eu sempre digo a eles, a escola é de vocês, a escola não é do diretor, a escola não é 
dos professores, a escola não é da cozinheira, a escola não é do apoio, a escola é de todos nós, a escola é nossa" (Profa. Begônia).

A estrutura da escola, para além de seu panoptismo 40 e dos efeitos dele esperados, apresentava um pátio principal que reunia, ao seu redor, a entrada da escola, a sala dos professores, os dois corredores de acesso às salas de aula e mais dois pátios, a secretaria, a diretoria, a cozinha, configurando um cenário que parecia colocar tudo e todos em cena: os sujeitos, o comer, a comida, as interações e as identidades. A estrutura pátios-corredores permitia que os alunos percorressem os espaços produzindo um movimento circular. Durante o período do recreio e do intervalo do almoço, diferentes arranjos de alunos, duplas, trios e grupos se formavam e davam voltas nesse circuito, brincando, correndo, caminhando, "desfilando", abraçados, "enganchados como corda de caranguejo", como dizia uma cozinheira.

Esse desenho propiciava um modo peculiar de mover-se - uma performance. Esse "círculo de interações", que ocorria em um espaço considerado pequeno para a quantidade de pessoas que circulavam nele, resultava em uma proximidade de atividades e sujeitos. Um "círculo" que permitia constantes e intensas interações para além da sala de aula, aproximando alunos, professores, diretora, cozinheiras, auxiliares e vigilantes. Em que pese a vigília referida anteriormente, a sociabilidade, a liberdade, a renovação, a fuga e pausa da sala de aula figuravam naquela cena, constituindo, também, identidades dissonantes da hegemônica.

Um movimento que era dialético, em que se observavam oscilações de satisfação e insatisfação com a escola nos discursos e práticas, envolvendo todas as categorias de sujeitos. Portanto, a escola é um ator social constituído a partir das estruturas de poder e também da agência dos seus membros que promovem o deslocamento das forças, reconstruindo identidades, assentadas numa configuração de resistência, conforme discute Castells 22, ante o enfrentamento dos estigmas que inferiorizam a escola pública e seus alunos, traduzidas em práticas estruturantes a reivindicar uma identidade não sujeitada.

Nesse passo, discutir as interações entre os diversos sujeitos da escola contribui para compreender como os sujeitos se posicionam e ou questionam práticas de poder e de dominação 40. Assim, o cotidiano da escola estudada aponta também processos de resistência que ressignificam a escola pública, pela inventividade e agência dos sujeitos que a constituem.

\section{"A comida é o que une": refeições compartilhadas, identidades partilhadas}

Busca-se analisar como a alimentação escolar se constitui em uma experiência significativa e identitária para os alunos, discutindo os mútuos efeitos entre alimentação escolar e identidades.

A alimentação é considerada uma atividade social importante, sendo um fator determinante nas relações humanas, seja no núcleo familiar, nos grupos sociais, na cidade, no estado-nação 19. Ou seja, comemos todos os dias e, parte desse comer o fazemos em meio a grupos e espaços sociais. Logo, a escola, além de ser um local de estudos e trabalho, é também um espaço de comida e comensalidade.

As refeições produzidas com os recursos do PNAE cumprem com o dever constitucional de garantir o direito dos alunos à alimentação no período em que permanecem na escola 41. Outrossim, a extensão da oferta dessa alimentação para outros sujeitos que atuam na escola é uma prática que foi observada na escola estudada, embora não seja isolada 42 . Ainda que tal prática possa ser questionável por não estar prevista no arcabouço normativo do PNAE, resta refletir acerca dos efeitos subjetivos que dela derivam. Parece-nos que não se trata aqui de uma alimentação dirigida apenas aos alunos e, como aludido anteriormente, eivada ainda de representações assistencialistas, mas de uma alimentação que todos podem comer, na direção de um direito que a todos assiste, em referência ao DHAA - premissa assumida pelo PNAE. Destarte, desloca-se a alimentação escolar do estigma que sobre ela pesa, inclusive historicamente, para significar uma partilha que altera sentido e identidade, da sujeição, da estigmatização, para afirmação de uma identidade valorizada, ressignificada.

Em entrevista, a diretora da escola referiu que, quando os alunos veem os professores e ela própria comerem as refeições produzidas na escola, parece ter um efeito de credibilidade à alimentação escolar, ante o fato de que os alunos chegam à escola com representações que a alimentação escolar não é boa, tal como revela a fala de Hibisco, que, além de refutar a representação estigmatizada sobre a alimentação escolar, a contextualiza como fruto de um processo valorizado e cuidadoso: “...eu só queria 
falar porque o povo de fora não conhece o colégio direito e surgem boatos dizendo que a merenda do colégio é isso, ou aquilo, eu não acho nada disso, porque a merenda do colégio é pensada, preparada, passa por reunião, passa por uma nutricionista, é tudo de qualidade" (Hibisco, 13 anos, oitavo ano).

As refeições do PNAE na escola estudada faziam parte das práticas alimentares dos alunos, dos funcionários e de uma pequena parcela dos professores. Mesmo que haja diferenças de gosto entre as categorias dos sujeitos presentes na escola, o cardápio parecia atender aos gostos e às necessidades, pelo menos na situação em que se encontravam, ou seja, o espaço de trabalho e estudo que os sujeitos compartilhavam. Assim, o consumo da alimentação escolar os reunia em torno de um comer comum. Ou seja, "uma alimentação comum pode produzir os mesmos efeitos que uma origem comum" 19 (p. 155).

Os significados atribuídos à partilha da alimentação escolar são expressivos das interações entre pares, professores e funcionários, constituídas na comensalidade que propiciava. De segunda a sexta, os alunos frequentam espaços escolares e, movidos pela fome e pelo próprio processo de construção identitária, constituem, junto com outros sujeitos, práticas alimentares nesse espaço social.

Práticas alimentares incluem alimentos e refeições que, por sua vez, abrigam significados e funções. Douglas 43 explica a função social da alimentação definindo a refeição como uma atividade social estruturante e organizadora do social. Essa função pode ser decifrada na alimentação escolar praticada no cotidiano das escolas, refletida na ritualização das refeições e incorporação dos seus elementos 44 , seja em sua dimensão biológica ou simbólica.

Em um primeiro plano, percebe-se o papel da alimentação escolar cumprindo sua função de socialização, no sentido bourdieano, ao se formar corpos dóceis e obedientes e no sentido da microfísica do poder foucaultiano, quando serve de recurso para incorporar regras, tais como ilustrado na escola estudada, a formação de filas durante a distribuição das refeições, a subordinação de alunos ante a ameaça das cozinheiras em não lhes servir quando chegavam para almoçar depois que a sua turma já tinha sido servida. Essas situações permitem perceber a materialidade das condições estruturadas de um habitus na escola, quando da oferta da alimentação escolar, a partir das quais a disciplina e regra operam por ações de dominação. Contudo, não foi visível situações nas quais o estudante era sujeitado à e pela comida, em paralelo ao aludido por Paiva et al. 10, quando observaram situações em que a comida comunicou a condição estigmatizada de pobreza do aluno, ou subordinando-o a ela.

Em um segundo plano, a alimentação escolar não figura apenas a serviço de um habitus estruturado, visto que outras experiências são construídas coletivamente a partir das intersubjetividades dos sujeitos. Assim, alunos, professores e funcionários compartilham um espaço, uma comida, um vínculo. Espaço, tempo e comida os impelem a interações capazes de transformar os significados dessa comida compartilhada. Inúmeros fatores concorriam para que, na escola estudada, a comida não fosse apenas uma questão disciplinar e de necessidade, mas também de afeto, de prazer, de comensalidade, de construção de vínculos e de pertencimento.

O contexto da alimentação escolar na escola estudada convergia para uma construção dinâmica e cotidiana de uma identidade compartilhada mediatizada pelo comer da mesma comida. Algumas características do modus operandi da escola e da alimentação escolar concorriam para que os distintos sujeitos que consumiam a alimentação escolar lhe conferissem credibilidade: até certo ponto, eles sabiam a origem dos gêneros (agricultura familiar e mercado local), situação essa que, de algum modo, contribuía para uma confiança na alimentação escolar; presumiam que era uma comida saudável porque a escola buscava atender as normativas do PNAE, as quais eram comunicadas pelas reuniões de colegiado; a comida era preparada por cozinheiras experientes e dedicadas; os alunos conheciam e davam credibilidade às cozinheiras; havia uma relação de afeto estabelecida entre cozinheiras e alunos; a localização da cozinha no pátio principal da escola propiciava uma proximidade com a alquimia da comida e permitia uma interação com o universo da cozinha, permeado de cheiros e "espiadas" através do balcão; e, por fim, essa comida era compartilhada com todos, todos os dias e, portanto, por meio de sua materialidade e simbolismo, constituía seus corpos e suas identidades.

Porém, esse compartilhar da mesma comida não pode ser visto de uma forma homogênea, porque também apresentava diferenças. Pratos e copos de vidro eram utilizados por adultos e de plásticos, por alunos; garfo e faca para os adultos, colher para os alunos. Apenas alguns funcionários da limpeza almoçavam no pátio próximo aos alunos ou em sala de aula enquanto os vigiavam, os demais funcionários e professores almoçavam em seus respectivos redutos, ou seja, a secretaria, a cozinha, a direção, 
a sala dos professores. Mesmo sendo a mesma comida, essas diferenças traçam fronteiras identitárias entre grupos e no interior de grupos 19 . Assim, considera-se que o comer a mesma comida reduzia as diferenças, mas não as eliminava.

Desse modo, o comer cotidiano na escola produzia uma comensalidade própria, construída e vivenciada pelos sujeitos, permeada por reciprocidades e proximidades, mas também por distinções.

Esse poder de construir uma identidade valorizada mediada pela alimentação escolar também pôde ser evidenciado nas palavras da diretora: "A comida é o que une, é o que une em todos os aspectos aqui. Quando faz um evento, que faz uma comida diferente, eles adoram, quando tem o almoço, mesmo reclamando, mas eles gostam, sabe, mesmo não tendo uma estrutura digna, (...), mas ainda assim, eles estão felizes" (Profa. Begônia).

Assim, comer a mesma comida unia todos em uma identidade partilhada, dinâmica, inacabada, plural, construída e ressignificada nas interações em torno das refeições do PNAE e, por conseguinte, dando legitimidade e reconhecimento à alimentação escolar.

\section{Considerações finais}

A discussão sobre as interações entre as práticas alimentares na escola e os processos identitários de estudantes não se esgota nas duas categorias destacadas neste artigo. As reflexões teóricas e empíricas sobre as práticas alimentares e os processos identitários ora realizadas levaram-nos a uma junção conceitual desses fenômenos, entendendo que ambos são abertos, fluidos e dinâmicos, sendo estruturas estruturadas e estruturantes da construção de significados e vínculos da relação sujeito e sociedade, em um dado contexto sócio-histórico. Ou seja, as interações entre práticas alimentares e processos identitários dos alunos em torno da alimentação escolar são instituintes de novas práticas com potencial de transformar significados e identidades dos sujeitos, da alimentação escolar e da própria escola.

A escola se configura como uma instituição que integra o sistema educacional, refletindo as ambiguidades desse sistema, ou seja, de um lado, a escola atua como aparelho da reprodução social, de outro, como possibilidade de uma formação emancipatória dos sujeitos. No contexto das escolas públicas brasileiras, identidades estigmatizadas são atribuídas à própria escola, aos alunos e à alimentação escolar, o que envida posturas para questionar a origem e o propósito desse estereótipo.

Os discursos e as práticas dos sujeitos da escola estudada apontaram para um movimento de resistência e de ressignificação das identidades escolares, no qual a alimentação escolar foi identificada como um elemento estruturante e articulador, evidenciando também a potência dos alunos de resistir e transformar práticas e identidades.

As experiências deslindadas da realidade estudada nos convidam a perguntar para que identidades as práticas alimentares no contexto do PNAE devem contribuir, haja vista o potencial de tanto servir a reprodução social como para a sua transformação. A escola estudada evidencia o quanto o diálogo entre o campo da educação e o da alimentação e nutrição pode contribuir para que a alimentação escolar se integre às práticas escolares não como um mero suporte nutricional, mas como comida que valoriza a escola pública e seus sujeitos. 


\section{Colaboradores}

E. O. Silva contribuiu com a concepção e delineamento do estudo e escrita do artigo. L. AmparoSantos e M. D. Soares contribuíram com a concepção e delineamento do estudo e revisão crítica do artigo.

\section{Informações adicionais}

ORCID: Edleuza Oliveira Silva (0000-0002-60708938); Lígia Amparo-Santos (0000-0002-69256421); Micheli Dantas Soares (0000-0002-07335319).

\section{Referências}

1. Andersen SS, Holm L, Baarts C. School meal sociality or lunch pack individualism? Using an intervention study to compare the social impacts of school meals and packed lunches from home. Social Science Information 2015; 54:394-416.

2. Andrade MAP. Preferências alimentares entre adolescentes: estudo de caso em Salvador, Bahia [Dissertação de Mestrado]. Salvador: Universidade Federal da Bahia; 2009.

3. Assao TY. Alimentação escolar: percepções dos atores sociais das escolas de um município da região metropolitana de São Paulo [Tese de Doutorado]. São Paulo: Universidade de São Paulo; 2012.

4. Freitas MCS, Minayo MCS, Ramos LB, Fontes GV, Santos LA, Souza EC, et al. Escola: lugar de estudar e de comer. Ciênc Saúde Coletiva 2013; 18:979-85.

5. Freitas MCS, Fontes GAV. Alimentação na escola pública: um estudo com adolescentes em unidades de ensino de municípios baianos. In: Freitas MCS, Fontes GAV, Oliveira N, organizadoras. Escritas e narrativas sobre alimentação e cultura. Salvador: EDUFBA; 2008. p. 37-54.

6. Mielniczuk VBO. Gosto ou necessidade? Os significados da alimentação escolar no Município do Rio de Janeiro [Dissertação de Mestrado]. Rio de Janeiro: Universidade Federal Rural do Rio de Janeiro; 2005.

7. Mortazavi M. Consuming identities: law, school lunches, and what it means to be American. Cornell J Law Public Policy 2014; 24:145.

\section{Agradecimentos}

O presente trabalho foi realizado com o apoio da Coordenação de Aperfeiçoamento de Pessoal de Nível Superior (Capes; Código de Financiamento 001); e também com o apoio da Fundação de Amparo à Pesquisa do Estado da Bahia (FAPESB).
8. Nukaga M. The underlife of kids' school lunchtime: negotiating ethnic boundaries and identity in food exchange. J Contemp Ethnogr 2008; 37:342-80.

9. Paiva JB, Freitas MCS, Santos LAS. Hábitos alimentares regionais no Programa Nacional de Alimentação Escolar: um estudo qualitativo em um município do sertão da Bahia, Brasil. Rev Nutr PUCCAMP 2012; 25:191-202.

10. Paiva JB, Freitas MCS, Santos LAS. Significados da alimentação escolar segundo alunos atendidos pelo Programa Nacional de Alimentação Escolar. Ciênc Saúde Colet 2016; 21:2507-16

11. Portronieri FRDS. O jovem, o comer e o perceber-se: concepções de alunos e professores sobre o corpo, a alimentação e a saúde em uma escola municipal do Rio de Janeiro [Dissertação de Mestrado]. Rio de Janeiro: Universidade Federal do Rio de Janeiro; 2010.

12. Stead M, McDermott L, MacKintosh AM, Adamson A. Why healthy eating is bad for young people's health: identity, belonging and food. Soc Sci Med 2011; 72:1131-9.

13. Theodore FL, Bonvecchio Arenas A, Blanco García I, Carreto Rivera Y. Representaciones sociales relacionadas con la alimentación escolar: el caso de las escuelas públicas de la Ciudad de México. Salud Colect 2011; 7:215-29.

14. Silva EO, Amparo-Santos L, Soares MD. Alimentação escolar e constituição de identidades dos escolares: da merenda para pobres ao direito à alimentação. Cad Saúde Pública 2018; 34:e00142617. 
15. Peixinho AML. A trajetória do Programa Nacional de Alimentação Escolar no período de 2003-2010: relato do gestor nacional. Ciênc Saúde Colet 2013; 18:909-16.

16. Bourdieu P. O senso prático. 2a Ed. Petrópolis: Editora Vozes; 2011

17. Fischler C. Food, self and identity. Social Science Information 1988; 27:275-92.

18. Freitas MCS, Minayo MCS, Fontes GAV. Sobre o campo da alimentação e nutrição na perspectiva das teorias compreensivas. Ciênc Saúde Colet 2011; 16:31-8.

19. Poulain JP. Sociologias da alimentação. Florianópolis: Editora da UFSC; 2004

20. Carvalho VD, Borges LO, Rêgo DP. Interacionismo simbólico: origens, pressupostos e contribuições aos estudos em psicologia social. Psicol Ciênc Prof 2010; 30:146-61.

21. Nunes JA. Erving Goffman, a análise dos quadros e a sociologia da vida cotidiana. Revista Crítica de Ciências Sociais 1993; (37):33-49.

22. Castells M. O poder da identidade. v. II. $8^{\mathrm{a}}$ Ed. São Paulo: Paz e Terra; 1999.

23. Hall S. Quem precisa de identidade? In: Silva TT, organizador. Identidade e diferença: a perspectiva dos estudos culturais. Petrópolis: Editora Vozes; 2000. p. 103-33.

24. Hall S. A identidade cultural na pós-modernidade. 12a Ed. Rio de Janeiro: Lamparina; 2015.

25. Bourdieu P, Passeron JC. La reproducción. Elementos para una teoría del sistema de enseñanza. México DF: Distribuciones Fontamara;1996.

26. Bourdieu P. A escola conservadora: as desigualdades frente à escola e à cultura. In: Nogueira MA, Catani A, organizadores. Escritos de educação. Petrópolis: Editora Vozes; 1998. p. 40-64.

27. Freire P. Pedagogia do oprimido. São Paulo: Paz e Terra; 1997.

28. Oliveira JF. A função social da educação e da escola pública: tensões, desafios e perspectivas. In: Ferreira EB, Oliveira DA, organizadoras. Crise da escola e políticas educativas. Belo Horizonte: Autêntica; 2009. p. 237-52.

29. Silva EO. Práticas alimentares e identidades escolares: uma etnografia sobre o cotidiano alimentar de uma escola pública de um município do Recôncavo Baiano [Tese de Doutorado]. Salvador: Universidade Federal da Bahia; 2018.

30. Geertz C. A interpretação das culturas. Rio de Janeiro: LTC; 2008.
31. Cunha SHP. Um retrato fiel da Bahia: sociedade-racismo-economia na transição para o trabalho livre no recôncavo açucareiro, 18711902 [Tese de Doutorado]. Campinas: Universidade Estadual de Campinas; 2004.

32. Melo MCS. Trajetórias ausentes: considerações sobre a invisibilização dos/as artistas plásticos/as negros/as no Recôncavo da Bahia [Dissertação de Mestrado]. Cachoeira: Universidade Federal do Recôncavo da Bahia; 2016.

33. Dubar C. A crise das identidades: a interpretação de uma mutação. Porto: Edições Afrontamento; 2006.

34. Sombra L. Fundamentos hermenêuticos e críticos do narrativo. In: Freitas MCS, Silva DO, organizadoras. Narrativas sobre o comer no mundo da vida. Salvador: EDUFBA; 2014. p. 9-32.

35. Gadamer HG. Verdade e método. Traços fundamentais de uma hermenêutica filosófica. 3a Ed. Petrópolis: Editora Vozes; 1999.

36. Rios TA. Identidade da escola. Associação Nova Escola. https://gestaoescolar.org.br/con teudo/714/identidade-da-escola (acessado em 07/Set/2018).

37. De Certeau M. A invenção do cotidiano: as artes do fazer. 3a Ed. Petrópolis: Editora Vozes; 1998.

38. Castro PA. Tornar-se aluno: identidade e pertencimento - um estudo etnográfico [Tese de Doutorado]. Rio de Janeiro: Universidade do Estado do Rio de Janeiro; 2011.

39. Sacristán JG. El alumno como invención. Barcelona: Ediciones Morata SL; 2003.

40. Foucault M. Microfísica do poder. 16a Ed. Rio de Janeiro: Edições Graal; 2001.

41. Brasil. Lei no 11.947, de 16 de junho de 2009. Dispõe sobre o atendimento da alimentação escolar e do Programa Dinheiro Direto na Escola aos alunos da educação básica. Diário Oficial da União 2009; 17 jun.

42. Bezerra JAB. Alimentação e escola: significados e implicações curriculares da merenda escolar. Rev Bras Educ 2009; 14:103-15.

43. Douglas M. Deciphering a meal. In: Geertz C, editor. Myth, symbol and culture. New York: Dedalus; 1972. p. 36-54.

44. Moreira SA. Alimentação e comensalidade: aspectos históricos e antropológicos. Ciênc Cult 2010; 62:23-6. 
Abstract

Studies on dietary practices in the scope of the Brazilian National School Feeding Program (PNAE) have identified a paradox: while the PNAE has progressed as a policy based on the human right to adequate diet, it has a paternalistic bias which tends to contribute to stigmatized identities. A study was thus performed to understand the interactions between dietary practices in school meals and identities. The theoretical and methodological approach was ethnographic, focusing on the scenario of a public school in the municipality (county) of Santo Antônio de Jesus, Bahia State, Brazil, in the upper years of elementary school. The ethnographic work was done in seven months, consisting of observation of daily meals at the school, recorded on a field diary, as well as 23 interviews with students and key actors. Analysis of the material consisted of a hermeneutic exercise and categorization of the emerging themes. This article is a cross-section of the study, presenting two categories: the first, "The school is ours", analyzes the redefinition of school in relation to a stigmatized identity; the second, "Food is what unites", presents school meals as a structuring element in students' identities and that of the school itself. The findings also show how the dialogue between the field of education and the field of food and nutrition can help school meals become part of school practices, not as mere nutritional support, but as food that values the public school and its members.

School Feeding; Feeding Behavior; Social Identification; Schools; Students

\section{Resumen}

Estudios sobre prácticas alimentarias en el contexto del Programa de Nacional Alimentación Escolar (PNAE) han apuntado una paradoja: por un lado, el PNAE avanzó como una politica basada en el derecho humano a una alimentación adecuada $y$, por otro, todavía presenta un sesgo asistencialista que tiende a contribuir a identidades estigmatizadas. Considerando este contexto, se realizó un estudio, con fin de comprender las interacciones entre las prácticas alimentarias en torno a la alimentación escolar y sus identidades. El enfoque etnográfico se configuró como una trayectoria teórico-metodológica, tomando como escenario una escuela pública en el municipio de Santo Antônio de Jesus, Bahía, Brasil, de segundo ciclo de enseñanza fundamental. La etnografía se realizó durante siete meses, estando constituida por observación del día a día alimentario de la escuela, con registros en un diario de campo, así como la realización de 23 entrevistas a alumnos y actoresclave. El análisis del material producido consistió en un ejercicio hermenéutico y categorización de los temas que emergieron. Este artículo es parte de esta investigación en la que se presentan dos categorías: la primera, "La escuela es nuestra", analiza un movimiento de redefinición de la escuela ante una identidad estigmatizada; la segunda, "La comida es lo que une", presenta la alimentación escolar como un elemento estructurante de las identidades de los alumnos y de la propia escuela. Los resultados apuntan también a que el diálogo entre el campo de la educación, y el de la alimentación y nutrición, pueden contribuir a que la alimentación escolar integre las prácticas escolares no como un mero soporte nutricional, sino como una auténtica comida que valora a la escuela pública y a quienes la componen.

Alimentación Escolar; Conducta Alimentaria; Identificación Social; Instituciones Académicas; Estudiantes
Recebido em 13/Nov/2018

Versão final reapresentada em 04/Abr/2019

Aprovado em 16/Mai/2019 